\title{
Nature a back number?
}

SIR - Your leading article about the Engineering and Physical Sciences Research Council (EPSRC), "An agency that is flexible but flawed" (Nature 379, 753; 1996), hints at an important issue, namely the design of procedures by which a research support agency can decide financial allocations to its different subject areas; the advice offered, however, is shown by your own arguments to be inadequate and the evidence on which the solutions are based is far from the truth.

Three statements can be put to the test. First, the "United Kingdom's physics community is having a rough time". This ignores the fact that, within the EPSRC, physicists have a higher level of funding support than any other community. The comparison with chemistry (the next largest group) is shown in the figure. If facilities are included, the advantage to physics is even greater. Furthermore, responsive mode proposals, where the topic is the choice of the applicant, have a success rate in the physics programme of $53 \%$ (chemistry 27\%) (EPSRC

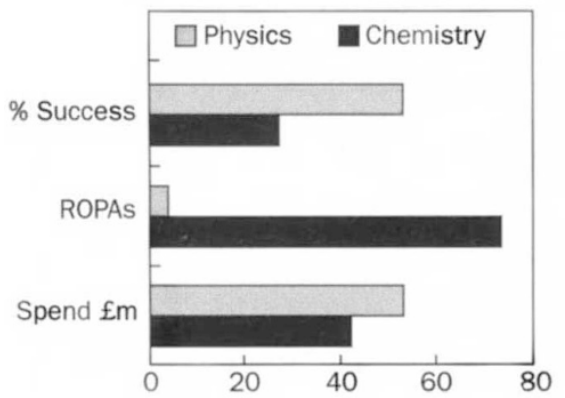

'\% Success' is for responsive mode proposals, by programme; 'ROPAs' is the number of proposals in 1995, by programme; 'Spend $\mathrm{fm}$ ' is spending by academic department (1994-95), covering grants and studentships.

letter to vice-chancellors, 4 October 1995). International comparisons suggest that this hardly corresponds to a "rough time".

Second, "the EPSRC is turning the screw". Even with allowance for editorial hyperbole, this seems an excessive reaction to the cut of approximately $3 \%$ to be made in the physics programme before the next prioritization exercise.

Third, "a relative lack of involvement with industry has counted against the physics community". The figure compares the actual lack of involvement as measured by ROPA applications, where $£ 25,000$ of industrial cash is a requirement for entry into the scheme. "Relative" or not, this level of involvement is surely an item for legitimate consideration.

You say that "if these areas are not suited to attracting funds from elsewhere, that is all the more reason why the EPSRC should reinforce its commitment to them": that would open the door to alarmingly wide abuse of the system. It will indeed be music to the ears of those promoting perpetual motion machines.

Research priorities must be established in a way that is effective and that can win the respect of the community. You complain that the "list of criteria... is dominated by factors relating to industrial potential". You publish these criteria and readers can therefore assess the extent to which they are "troublesome". The positive treatment of both chemistry and mathematics when exposed to such criteria should, however, provide reassurance about the flexibility of their impact.

In seeking solutions, you suggest that "standing disciplinary committees" are a regrettable absence from our prioritization procedures as we issue "signals that physicists are not doing as well as others in coming up with good ideas". You yourself recognize, however, the precise weakness of such committees in this role when you ask "what learned society would sensibly start choosing winners and losers from among its membership?"

The system the EPSRC has in fact set in place must undergo refinement in the light of experience; it is, however, founded on three simple statements that would, I hope, find sympathy with the wider community:

(1) Project selection must be made by peer review. Your disingenuous reference to "colleges" conceals the fact that these are formal assemblies of peer reviewers nominated by the research community (EPSRC Colleges, and a Guide to Peer Review, October 1995). Our programme managers are in post to manage the peer review process and not to carry out peer review itself. The model of the US National Science Foundation has been expressly avoided in all UK research councils precisely because of the powers of selection that it places in the hands of single individuals, even if "drawn from their communities".

(2) In the classical disciplines, including physics and engineering, the task of creative research thinking is best left to the individual scientist. The comprehensive strategic directives from the former 'standing disciplinary committees' (which also conducted the subsequent peer review) have been replaced by two-page 'landscapes' (EPSRC Programme 1995-96, March 1995) of priority indicators reflecting the thinking, for example, of the Government Foresight Exercise.

(3) Priority setting must be flexible. Under the present process, carried out by Council annually, decisions benefit from the comments of all interested parties on the published statement (already reprinted three times on demand) of research priorities (EPSRC programme 1995-96, March 1995). The accumulated comment is reviewed by the Council's two senior panels (Newsline January 1995) together with information from the Foresight Exercise and from programme managers on the current portfolios of the programme areas. The two panels then debate priorities and advise Council. You are entitled to propose other methods, but standing disciplinary committees have not shown themselves to be well fitted to the task.

The EPSRC has perhaps been "radical and innovative" and there will undoubtedly be strengths and weaknesses in the aftermath of the changes. With constructive comment (and this has been received) the weaknesses are being addressed. The benefits of the new system (to which you make scant allusion) are, however, surely significant. They include:

- higher success rates

- faster response times

- more open and participative peer review

- open and succinct priority statements

- absence of submission deadlines

- sympathy to interdisciplinary themes (absence of community 'territories')

A global dismissal of the new system prompted by concern that the physics community may find it difficult to defend its funding position is patronizing to physics colleagues. More seriously, it reflects a disappointing rejection of the "radical and innovative", whatever its merits. Nature finds itself clutching instinctively to the habits of yesteryear.

Richard J. Brook

(Chief Executive)

Engineering and Physical

Sciences Research Council,

Polaris House, North Star Avenue,

Swindon SN2 1ET, UK

\section{Knowing birds}

SIR - Your review of Nan Dunbar's inspiring edition of The Birds has drawn attention to Aristophanes' contribution to ancient ornithology. But even earlier, the poet Pindar, in about $500 \mathrm{BC}$, reported that Zeus had practical knowledge of avian ethology. (Pindar's account, since lost, was known to Strabo, the earliest geographer: see H. L. James (trans. and ed.), The Geography of Strabo, Heinemann, 1923.)

Zeus wanted to find the centre of the Earth, so he started two eagles of equal speed at the same moment, one from the eastern edge of the world, one from the western. They met at Delphi, and thus his putative hypothesis, presumably conceived on Olympus, was not refuted. The omphalos marks the spot where they fell, stunned by their collision. If this account is accurate, Zeus should, at last, be given credit for performing the first scientific experiment.

John Godfrey

41 Lawford Road, London NW5 2LG, UK 